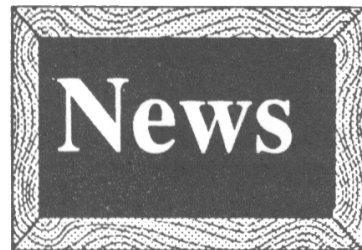

\section{Educators Focus on Indigenous Issues}

\section{Eugénie Fitzgerald}

Educators who successfully introduce indigenous issues into the classroom are helping to realise the vision of a socially just and inclusive Australian curriculum in the 21 st century, according to two guest speakers at a recent vacation school for teachers.

Koori Education Programs Officer at Melboume's Catholic Education Office, Peter Clarke, and Basil Varghese of the Victorian branch of the Brotherhood of St Laurence, said teachers did not have to be the victims of change - they could make change happen if they had power over resources, relationships, decision-making and information.

In plenary and workshop sessions held at the summer school run by the Australian Teaching Council and the National Schools Network, Mr Clarke and $\mathrm{Mr}$ Varghese encouraged participants to consider how they could help to create an inclusive and just society and education system.

'Apart from just supporting the ideal of acquiring skills, it is important for teachers to help students acquire a moral sense of what our responsibilities are to one another,' Mr Varghese said. 'This responsibility can be considered in terms of the student as a citizen of this country and in terms of working for a fair and just Australia.' Mr Clarke said participants had discussed the fundamental principles of negotiation and consultation with indigenous people and communities in the delivery of Koori education in their schools.

'Teachers have been exploring a number of key issues in terms of becoming change agents in their schools to get Aboriginal issues on the agenda and to move towards an indigenous inclusive curriculum,' he said. We talked about reconciliation as being the vehicle to carry us into the 21 st century vision of a socially just and inclusive education system.'

Participants then conducted an activity called the 'Wall of Prejudice' which involved the teachers writing down issues they thought were barriers to reconciliation and pasting them to cardboard boxes.
The cardboard boxes were stacked in a wall, providing a visual representation of the barriers to reconciliation.

On the final day of the conference, participants deconstructed the wall by suggesting effective ways of overcoming the barriers.

'As a metaphor, I stood behind the wall and said, "this wall appears when I, as an Aboriginal person, walk into a shop and three non-Aboriginal people walk in behind me and they are served first",' Mr Clarke said.

Both Mr Varghese and Mr Clarke felt their contact with teachers through the summer school had reaffirmed their commitment to working in the social justice area.

'If they are a snapshot of the kind of people around the country who are concerned about equity and justice, then we're very optimistic about what the future holds for Aboriginal and Torres Strait Islander kids,' Mr Clarke said.

'At the same time we don't want to let anybody lose sight of the broader issues including health, legal and political issues, because without those things it's a bit like putting the cart before the horse. If teachers don't have this deeper understanding and awareness, the whole intent behind putting indigenous perspectives on the agenda is in real danger of backfiring.'

Through a number of years work in the professional development field, Mr Clarke has concluded that the most effective courses in this area are conducted by, or in conjunction with, indigenous people.

The professional development courses he runs are based on the principle of negotiation, so in whichever community he works, he consults with the indigenous members of that community.

$\mathrm{Mr}$ Varghese and Mr Clarke explored a number of professional development issues including:

- Train the Trainer programs for Aboriginal and non-Aboriginal teachers

- anti-racism training and awareness

- cross-cultural communication

- collaboration with indigenous education and community members in the design, implementation and evaluation of curriculum.

More than 200 teachers and teacher-educators attended the conference at the University of Queensland.

Editor's Note: This article appeared in Education Views on 2 February 1996 and is reprinted with permission of the Public and Media Relations Branch of the Queensland Department of Education. 
The Aboriginal Child at School - Available Back Issues

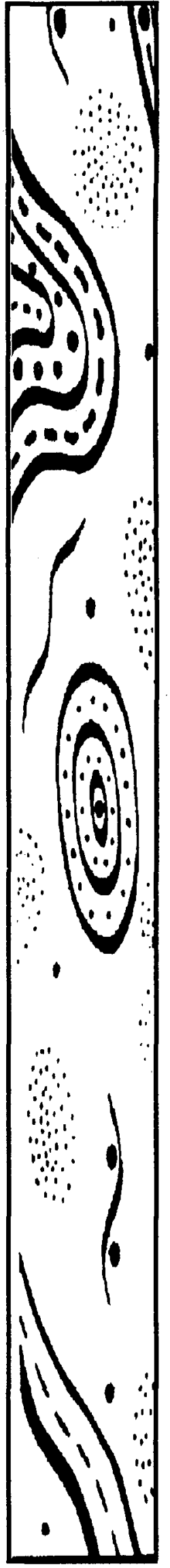

\begin{tabular}{|c|c|c|c|c|}
\hline $\begin{array}{l}\text { Volume } \\
\text { each }\end{array}$ & Number & Year & $\begin{array}{l}\text { Quantity } \\
\text { Required }\end{array}$ & Cost@\$5.00 \\
\hline 5 & 3 & 1977 & & \\
\hline 6 & 1 & 1978 & & \\
\hline 11 & 2 & 1983 & & \\
\hline 12 & 2 & 1984 & & \\
\hline 12 & 4 & 1984 & & \\
\hline 12 & 5 & 1984 & & \\
\hline 14 & 2 & 1986 & & \\
\hline 14 & 5 & 1986 & & \\
\hline 15 & 1 & 1987 & & \\
\hline 15 & 4 & 1987 & & \\
\hline 16 & 2 & 1988 & & \\
\hline 16 & 3 & 1988 & & \\
\hline 16 & 4 & 1988 & & \\
\hline 16 & 5 & 1988 & & \\
\hline 17 & 1 & 1989 & & \\
\hline 17 & 2 & 1989 & & \\
\hline 17 & 4 & 1989 & & \\
\hline 17 & 5 & 1989 & & \\
\hline 18 & 3 & 1990 & & \\
\hline 18 & 5 & 1990 & & \\
\hline 19 & 1 & 1991 & & \\
\hline 19 & 2 & 1991 & & \\
\hline 19 & 3 & 1991 & & \\
\hline 19 & 4 & 1991 & & \\
\hline 19 & 5 & 1991 & & \\
\hline
\end{tabular}


The Aboriginal Child at School - Available Back Issues

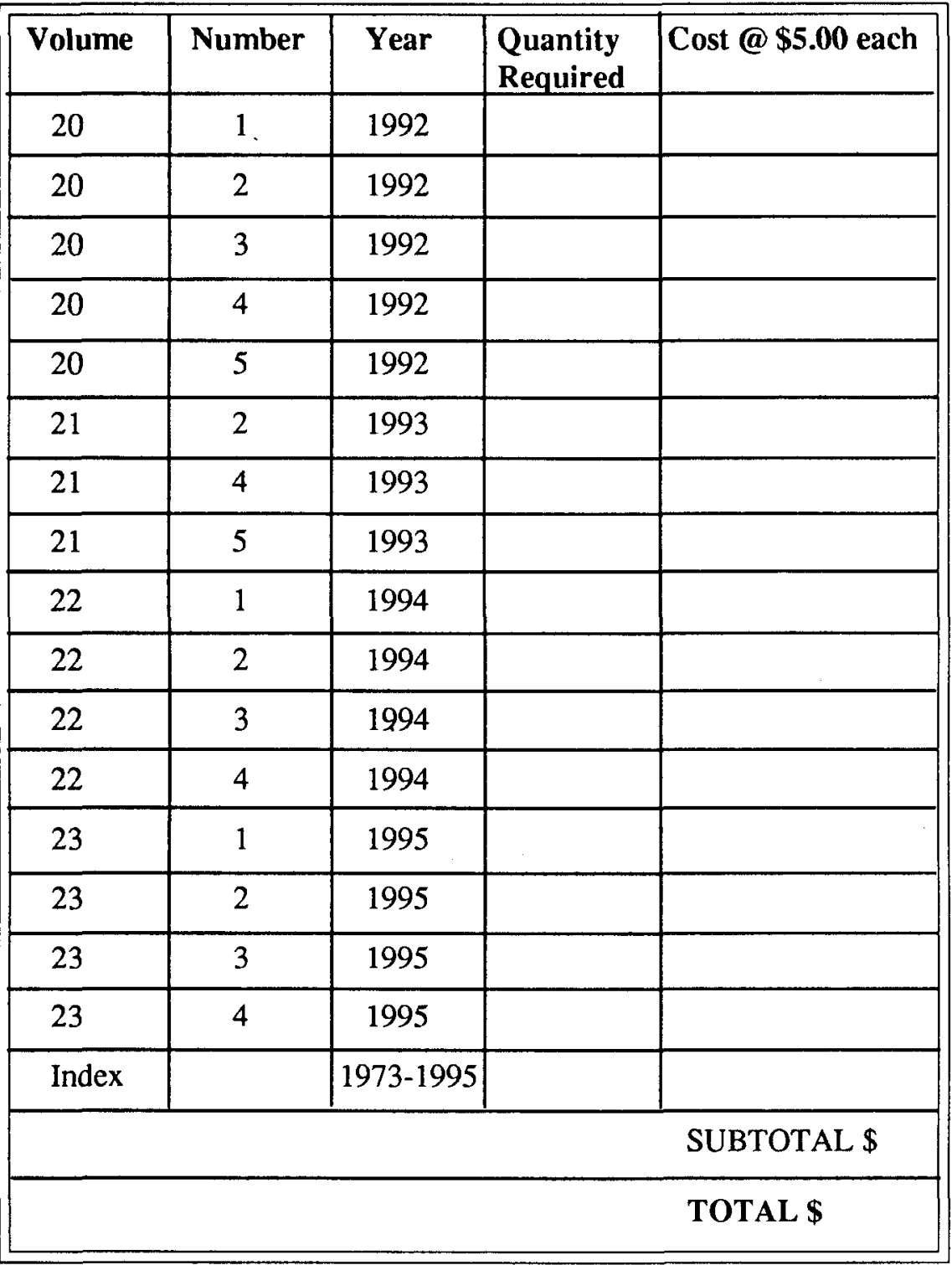

NAME:

ADDRESS:

STATE:

POSTCODE:

TOTAL ENCLOSED:

$\$$

(Please send cheque or money order payable to The University of Queensland)

The Australian Journal of Indigenous Education Aboriginal and Torres Strait Islander Studies Unit

The University of Queensland

Brisbane QLD 4072 AUSTRALIA

Ph: (07) 33656699 Fax: (07) 33652359

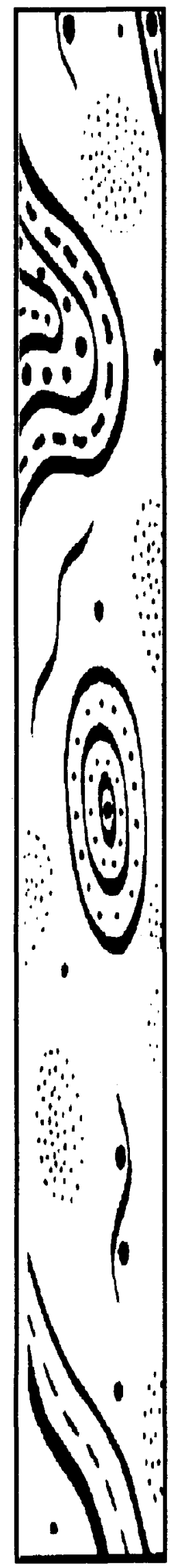

